\title{
Repopulation techniques for Macrocystis integrifolia (Phaeophyceae: Laminariales) in Atacama, Chile
}

\author{
Renato Westermeier • Pedro Murúa • David J. Patiño • \\ Liliana Muñoz • Carlos Atero • Dieter G. Müller
}

\begin{abstract}
The giant kelp Macrocystis (integrifolia) has been intensely harvested in northern Chile for several years. In order to prevent a future disaster, we developed two different techniques for restoration of damaged Macrocystis integrifolia beds in the Atacama region of Chile. (1) Explantation: Laboratory-grown juvenile sporophytes were fixed to different substrata (plastic grids, ceramic plates, or boulders) by elastic bands or fast-drying glue (cyanoacrylate). Explants reached $150-200 \mathrm{~cm}$ in length within 5 months (relative growth rate $\approx 1.3-1.7 \%$ day ${ }^{1}$ ), and reproductive maturity in 5-7 months. (2) Seeding of spores: Mature sporophylls were placed at $8 \mathrm{~m}$ depth on the sea bottom, supported by cotton gauze sleeves attached to boulders of different origin. Sixty percent of clean boulders collected on the beach produced up to seven recruits per boulder. In contrast, $20 \%$ of the boulders from the sea bottom, colonized by epibionts, showed up to two recruits. Relative growth rates, however, were similar $\left(\approx 2.4-2.6 \%\right.$ day $\left.{ }^{1}\right)$. Practical applications of our findings are: laboratory-produced juvenile sporophytes fixed to various substrata by elastic bands or cyanoacrylate glue can be used to colonize rocks or artificial reefs. In cases, where laboratorygrown seedlings are unavailable, mature sporophylls from nearby Macrocystis beds can be used to establish new recruits on rocky substrata.
\end{abstract}

Keywords Atacama - Chile - Cotton gauze sleeve · Cyanoacrylate glue · Elastic band - Macrocystis integrifolia . Repopulation · Sporophyll

R. Westermeier $(\bowtie) \cdot$ P. Murúa $\cdot$ D. J. Patiño $\cdot$ L. Muñoz $\cdot$ C. Atero Instituto de Acuicultura, Universidad Austral de Chile, Sede Puerto Montt, Casilla, 1327 Puerto Montt, Chile

e mail: rwesterm@uach.cl

D. G. Müller

Fachbereich Biologie der Universität Konstanz,

Konstanz 78457, Germany

\section{Introduction}

Macrocystis integrifolia, commonly known as giant kelp, is an important natural resource in northern Chile. It is intensely harvested for abalone feed and alginate manufacture in the Atacama region (Westermeier et al. 2012a). Furthermore, Macrocystis has been suggested as marine biomass for ethanol production (García et al. 2011), promoting expectations for kelp fisheries and mariculture along the coast of Chile.

Currently, M. integrifolia in northern Chile is likely to face unfavorable prospects.

1. Growing demand and decreasing availability of natural stocks are reported for recent years (Sernapesca 2011), which are likely to lead to resource depletion in the near future.

2. M. integrifolia is especially fragile under external stress factors such as El Niño, anthropogenic pollution, and overexploitation (North 1971; Westermeier et al. 2012b).

3. Although $M$. integrifolia dominates kelp forests of northern Chile in coverage and biomass, natural beds are discontinuous, and a damaged area has low chances for natural recovery from adjacent kelp stands.

In consequence, studies on population dynamics, management, and restoration techniques are not only important for ecological aspects, but also crucial for future legal and administrative actions. Recent reports indicate great potential for natural repopulation of $M$. integrifolia from Bahia Chasco, especially after harvesting campaigns. Natural recruitment depends mainly on season of the year and substratum availability (Westermeier et al. 2012b). In addition, Westermeier et al. (2013a) found that M. integrifolia holdfast fragments easily regenerate and the authors suggested a technique on this basis for recovery projects of kelp beds. Only few reports describe repopulation experiments with the intertidal kelp Lessonia nigrescens in Chile (Vásquez and Tala 1995; 
Correa et al. 2006), and no studies are known for $M$. integrifolia. Thus, our present report is the first attempt in Chile to elaborate techniques for repopulation of this kelp species via explantation of laboratory-grown juvenile seedlings and spore seeding by sporophylls from nearby kelp stands.

\section{Materials and methods}

Our experiments were conducted in Bahia Chasco $\left(27^{\circ} 41^{\prime} \mathrm{S}\right.$; $71^{\circ} 00^{\prime} \mathrm{W}$; Fig. 1a), Atacama Region, $60 \mathrm{~km}$ South of Caldera City between June 2011 and October 2012. This time span included a cloudy winter season with little rainfall and sunny summer days. Seawater temperature ranged between 13.5 and $19.0{ }^{\circ} \mathrm{C}$. Bahia Chasco offers one of the most important $M$. integrifolia populations of northern Chile. It supports more than 40 fishermen with 15 boats who harvest up to $40 \mathrm{t}$ day ${ }^{1}$ of fresh biomass for abalone producers (Fig. 1b).

Laboratory production of juvenile sporophytes

We followed the techniques described by Westermeier et al. (2005, 2006). Mature sporophylls of M. integrifolia were collected on November 2010 at Bahia Chasco, cleaned from epibionts, and transported at $\approx 8{ }^{\circ} \mathrm{C}$ to our culture facilities in Puerto Montt. Sorus areas were cut out, rinsed in fresh water, and softly dehydrated. Spore release occurred after reimmersion in Provasoli medium (PES; Starr and Zeikus 1993). Spore suspensions were introduced into sealable polyethylene bags with $400 \mathrm{~mL}$ PES medium and exposed to culture conditions of $25-50 \mu \mathrm{mol}$ photons $\mathrm{m}^{2} \mathrm{~s}^{1}$ from daylight-type fluorescent lamps, 16:8 (light/dark), and $12{ }^{\circ} \mathrm{C}$. After 1 week, settled spores were detached by soft manipulation of the plastic bags (Westermeier et al. 2005). Subsequent gametophyte growth, gametogenesis, fertilization, zygote germination, and early sporophyte development occurred inside the bags. When sporophytes reached $0.1 \mathrm{~mm}$ in size, cultures were expanded into glass bottles with aeration (1, 2, and $5 \mathrm{~L})$, acrylic cylinders (15-50 L), and greenhouse tanks (1,000 L). At an age of 30 weeks, when the sporophytes had reached $6-10 \mathrm{~cm}$ in length and formed basal haptera (Fig. 2a), they were ready for explantation to the sea at Bahia Chasco (Westermeier et al. 2006). Growth measurements and culture medium replacements were performed weekly.

Experiments on M. integrifolia repopulation in Bahia Chasco

We explored two strategies for repopulation of deteriorated $M$. integrifolia habitats: (1) explantation of sporophyte seedlings fastened to different substrata and (2) a spore-based technique employing direct inoculation of spores onto rocky substrata.
Fixation of juvenile sporophytes on rocks and artificial substrata

On June 2011, laboratory-grown seedlings with welldeveloped haptera (Fig. 2 a) were fixed by rubber elastic bands to plastic grids, ceramic plates, and irregular subglobular boulders of 20-30 cm diameter (Fig. 2b-d). Seedlings were also fixed directly to boulders with the fastdrying glue cyanoacrylate (Gel $10^{\circledR}$, Aron Alpha, Japan; Fig. 2e). All treatments contained 15 replicates, which were placed at $8 \mathrm{~m}$ depth. Sporophyte size (length in $\mathrm{cm}$ ) and reproductive phenology ( $\%$ reproductive individuals) were determined in monthly intervals.

Spore seeding by sporophyll translocation

Mature sporophylls of $M$. integrifolia with similar sorus size were collected by Hooka divers on November 2011 from Bahia Chasco at $8 \mathrm{~m}$ depth (Fig. 3a). They were cleaned, rinsed in freshwater, and mildly dried with

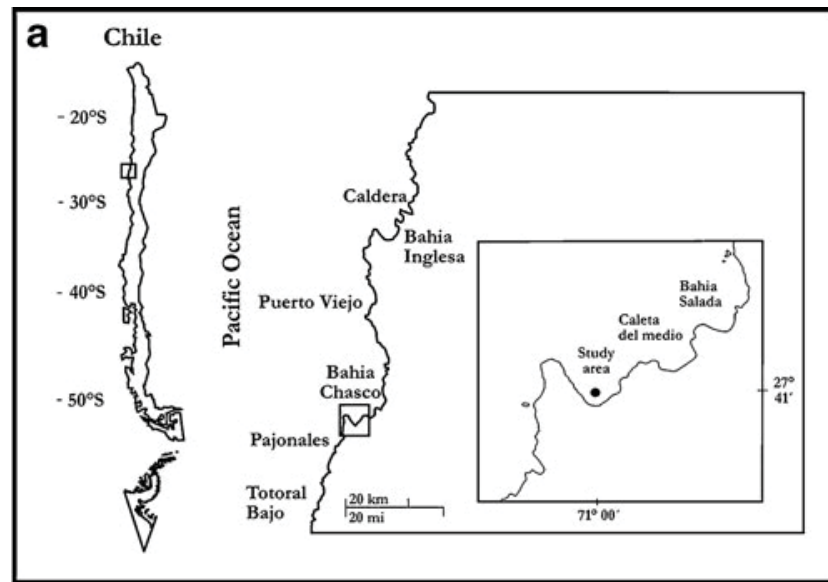

b

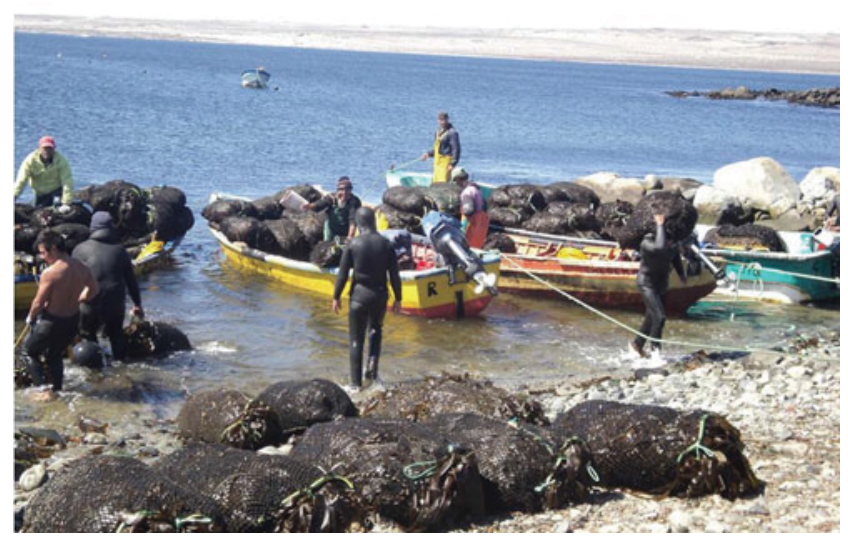

Fig. 1 Location of experimental site. a Study area, Bahia Chasco, Atacama region, Chile. b Local fishermen landing $M$. integrifolia packed for transport to abalone aquaculture facility 
Fig. 2 Initial and advanced stages of explanted $M$. integrifolia seedlings. Different substrata and attachment methods. Arrows initial holdfasts with early haptera. a Seedlings from our production line in UACh, Puerto Montt, ready for explantation in $\mathrm{B}$. Chasco. b d Explanted young sporophytes in the sea with their supports: b plastic grid, c ceramic plate, $\mathbf{d}$ beach boulder with elastic band, e beach boulder with cyanoacrylate glue. $\mathbf{f} \mathrm{j}$ Older explants established on their bases: $\mathbf{f}$ on plastic grid, $\mathbf{g}$ on ceramic plate, h $\mathbf{j}$ on beach boulders
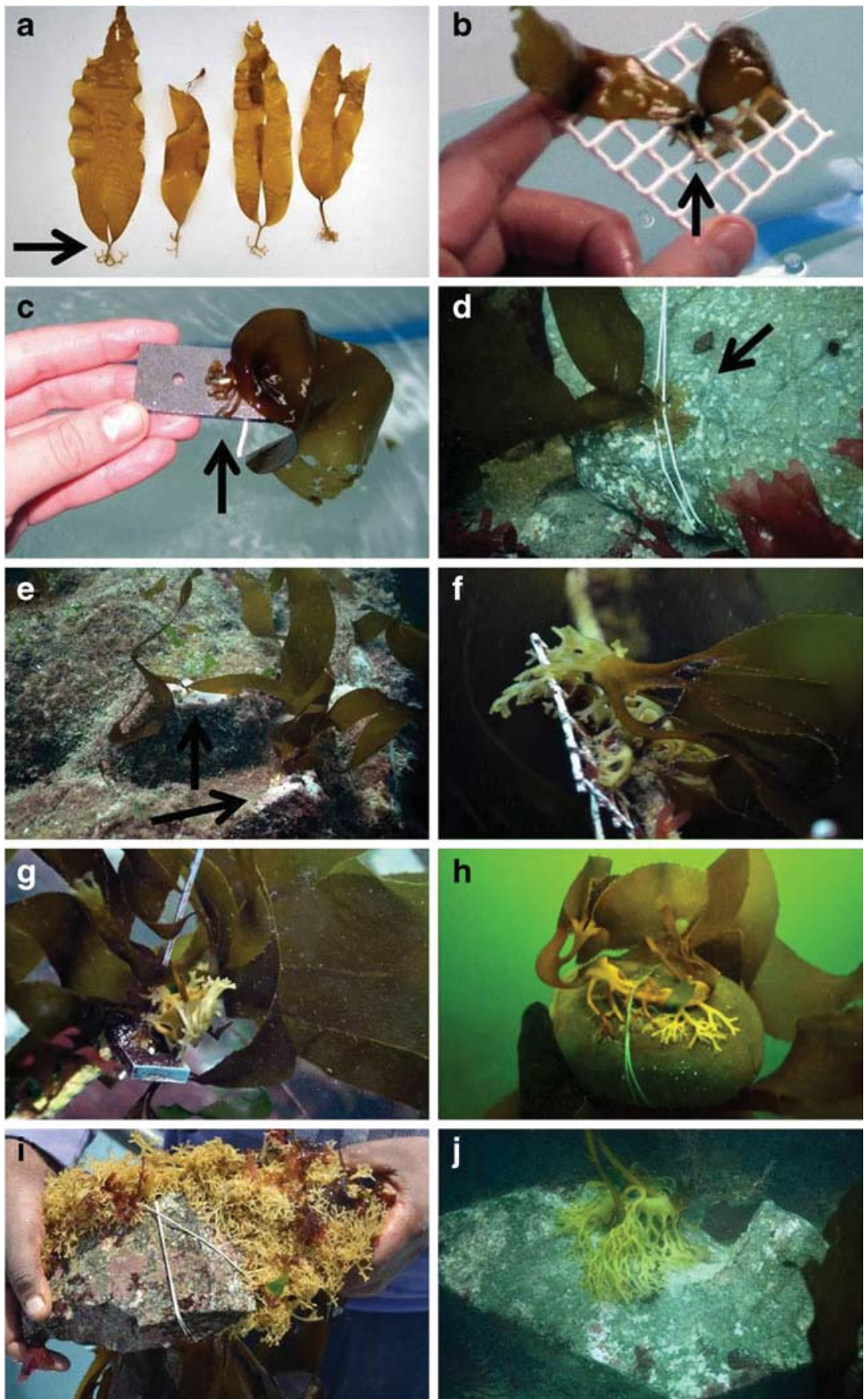

paper towel. Individual sporophylls from different specimens $(n=15)$ were loosely inserted into cotton gauze sleeves, in which beach and sea bottom boulders was previously introduced (Fig. 3b-d). Furthermore, either beach and sea bottom boulders were exposed without sporophylls as controls ( $n=15$ per treatment; Fig. $3 \mathrm{c}, \mathrm{d})$. While boulders from the beach were clean and could be used directly, boulders from the sea bottom were cleaned with diving knife to remove epibionts before attaching sporophylls. Monthly monitoring recorded recruitment effectiveness $(\%$ boulders with recruits), recruit density (recruits boulder ${ }^{1}$ ), and sporophyte size $(\mathrm{cm})$.

Comparison of growth rates and repopulation systems

Growth rates in each repopulation system were expressed as relative growth rate (RGR; \% day ${ }^{1}$ ), and estimated after Evans (1992): RGR $\left(\%\right.$ day $\left.{ }^{1}\right)=100\left[\left(\ln L_{f}-\ln L_{i}\right)\right] / \Delta t$; where $\ln L_{f}$ is the natural logarithm of final length, $\ln L_{i}$ is the natural logarithm of initial length, and $\Delta t$ is the 
Fig. 3 Spore seeding and subsequent recruitment of $M$. integrifolia. a Reproductive frond (sporophyll) with sporangial sorus (arrow). b c Boulder type substrata: $\mathbf{b}$ beach boulders, c sea bottom boulder; d cotton gauze sleeve holding seeding sporophyll on substratum. e f Results of spore seeding on sea bottom boulders: e early recruits (arrows), f young sporophytes
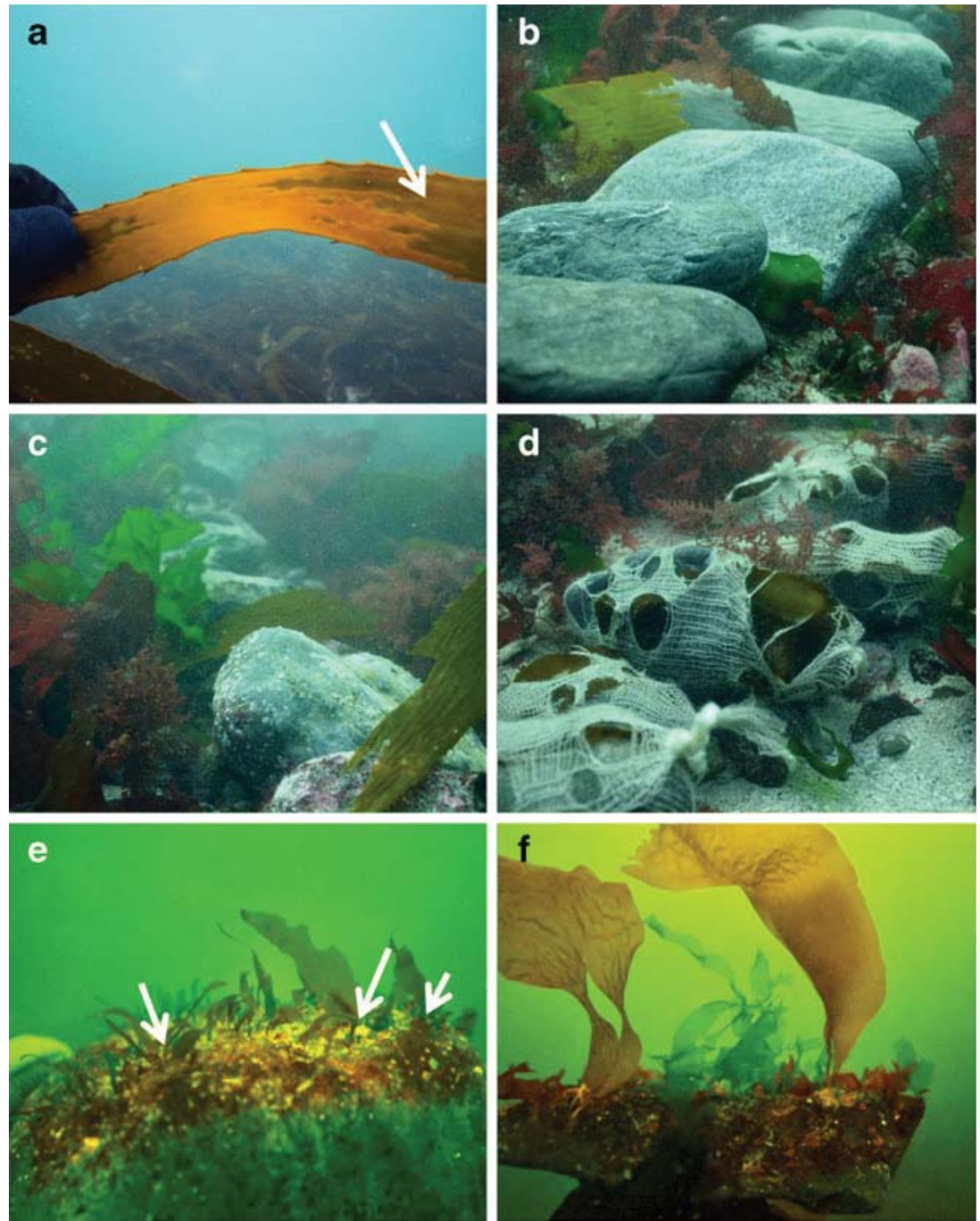

experimental time period in days. For determining RGR of direct sporophylls treatments, we used initial and final lengths at the beginning of the experiment and after 6 months, respectively. The RGR were analyzed and compared with a $5 \%$ level of confidence by one-way analysis of variance (ANOVA) test (Zar 1999) after normality and homoscedasticity assumptions.

\section{Results}

Production of $M$. integrifolia sporophytes in laboratory cultures

Three weeks after inoculation of spores, the first multicellular sporophytes appeared and reached $100 \mu \mathrm{m}$ in size by 5 weeks. At this stage, the sporophyte batches were transferred into glass bottles of increasing volume with continuous aeration. At the age of 17 weeks and a size of $9 \mathrm{~mm}$, sporophyte batches contained a minimum of $20^{4}$ seedlings and were expanded into acrylic cylinders and finally at a size of $30 \mathrm{~mm}$ to $1,000 \mathrm{~L}$ greenhouse tanks. At an age of 30 weeks, juvenile sporophytes reached $10 \mathrm{~cm}$ in length with well-developed blade, stipe, and haptera (Fig. 2a). Figure 4 shows sporophyte growth in a typical production line with Bahia Chasco seedlings.

Repopulation experiments: growth and reproductive phenology

\section{Sporophyte seedlings}

Monthly variations of size and reproductive phenology in sporophyte-based repopulation systems are illustrated in Fig. 5. Toward spring (Nov-Dec 2011), individuals within all treatments reached maximum sizes and reproductive maturity, followed by a decrease of both indexes in summer (Feb-Mar 2012) due to thallus erosion. Seedlings inoculated 


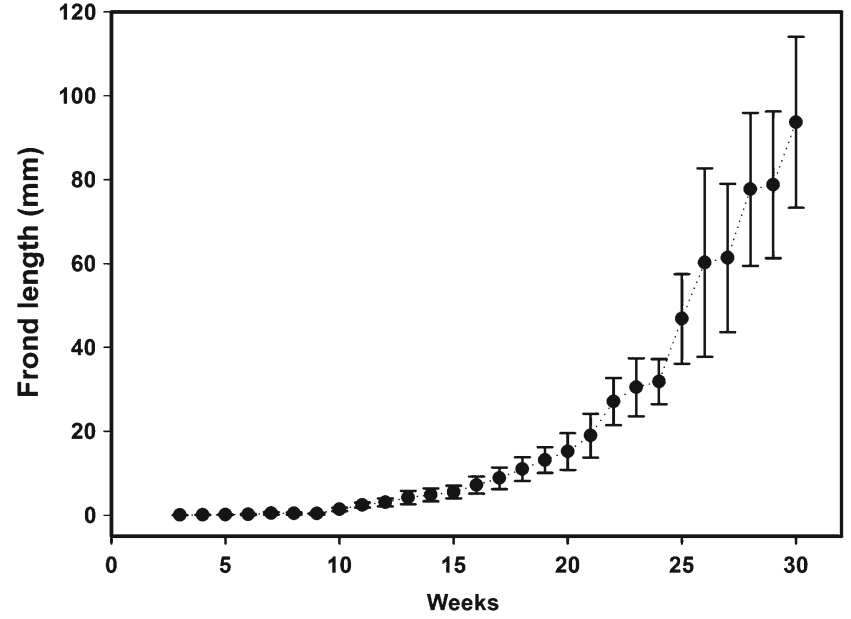

Fig. 4 Growth performance of M. integrifolia from Bahia Chasco in our Puerto Montt seedling production line, from meiospore suspension to haptera formation on juvenile sporophytes. Error bars indicate standard deviation

on boulders using elastic bands and cyanoacrylate glue showed best growth, reaching 228 and $226 \mathrm{~cm}$, respectively, in 6 months (Fig. 5c, d). Plastic grid individuals exhibited lower growth, reaching $188 \mathrm{~cm}$ within 5 months (Figs. $2 \mathrm{f}$ and $5 a)$, and lowest growth was recorded with thalli on ceramic plates, reaching only $155 \mathrm{~cm}$ during 8 months of culture (Figs. $2 \mathrm{~g}$ and $5 \mathrm{~b}$ ). Although growth rate differences among experimental groups (Fig. 6) were not statistically significant, sporophytes fastened to boulders with elastic bands and cyanoacrylate tended to grow faster (1.69 and $1.68 \%$ day ${ }^{1}$ ) than specimens fixed to ceramic plates (RGR $1.30 \%$ day ${ }^{1}$; $p>0.05)$.

\section{Spore inoculation}

Results of direct sporophyll repopulation experiments are shown in Figs. 3 and 7. After a few weeks in the sea, cotton gauze sleeves disintegrated, and the exhausted sporophylls were removed. First recruits were detected 3 months later (Fig. 3e) on beach and sea bottom boulders with 60 and $20 \%$ effectiveness (Fig. 7a). Recruit density and growth were highly variable (SD up to $70 \%$ of average values) with a tendency of better recruitment on beach boulders ( six recruits beach boulder ${ }^{1}$ ), compared with two recruits sea bottom boulder ${ }^{1}$. Regardless of boulder type, all thalli reached lengths of over $230 \mathrm{~cm}$ in 12 months of sampling. Sporophyte growth on sea bottom boulders reached $3.71 \%$ day ${ }^{1}$, slightly higher than $3.64 \%$ day ${ }^{1}$ seen on beach boulders. In contrast, control boulders without contact to sorus tissue showed no recruits (Fig. 7a). One-way ANOVA revealed statistical differences between RGRs, with higher values for sporophylls treatments $(p<0.05)$.
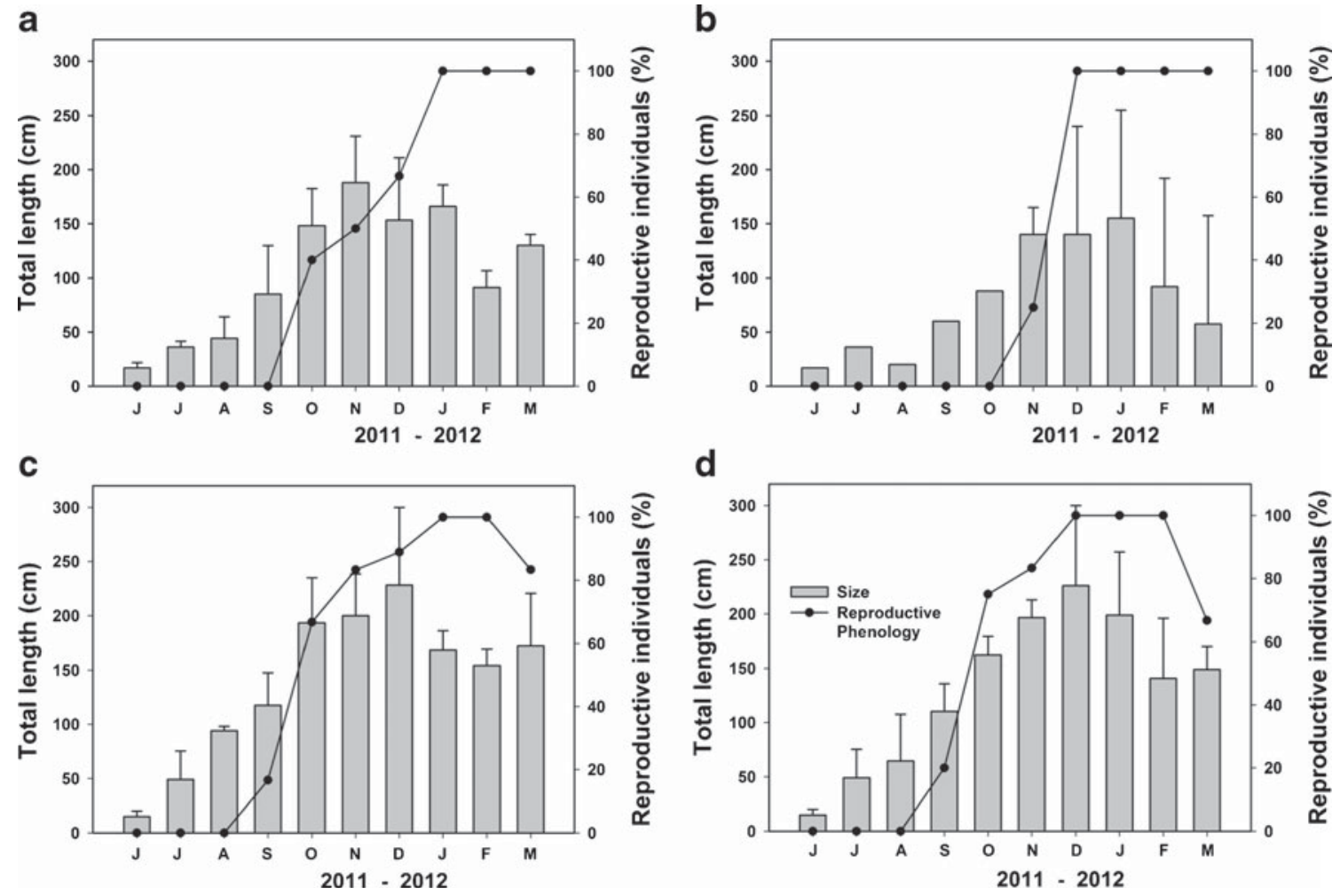

Fig. 5 Growth and reproductive phenology of $M$. integrifolia sporophyte explants fixed to different substrata. a Plastic grids, b ceramic plates, c boulder with elastic band, d boulder with cyanoacrylate glue. Error bars indicate standard deviation 


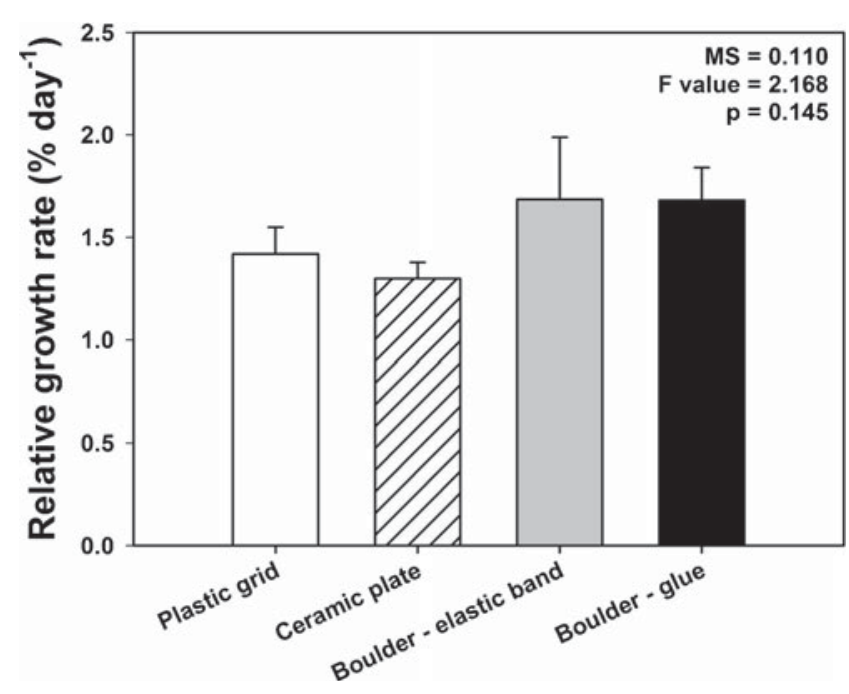

Fig. 6 Relative growth rates for explants of M. integrifolia sporophytes on different support and attachment method. Error bars indicate stan dard deviation

\section{Discussion}

Two species of Macrocystis exist along the coast of Chile: $M$. integrifolia and Macrocystis pyrifera. They are geographically separated, but occur sympatrically in Peru and North America. Based on interfertility (Westermeier et al. 2007) and supported by molecular data, Demes et al. (2009) and Macaya and Zucarello (2010) suggested their conspecificity under the name $M$. pyrifera. A valid taxonomic revision of the genus, however, is still lacking. Since the two taxa show differences in morphological and physiological features, which are of key importance for maricultural concern (e.g., the stoloniferous holdfast of $M$. integrifolia), we maintain the binomial $M$. integrifolia for the time being.

Previous mariculture attempts with $M$. integrifolia have used direct inoculation of spores on ropes. After growth of embryos up to 5-10 $\mathrm{mm}$ in the hatchery, ropes were transferred to installations in the sea (Stekoll and Else 1996; Macchiavello et al. 2010). This direct rope seeding technique can be considered as an inexpensive model for kelp restoration programs. However, it is subject to high risks of failure due to seasonal variations, fouling, sedimentation on the sea bottom, and herbivory (Vásquez and Tala 1995; Carney et al. 2005; Westermeier et al. 2012b). Laboratory-produced spores or small recruits often die off when translocated to the sea, since they cannot tolerate new environmental and biotic conditions (Carney et al. 2005; Westermeier et al. 2012b). Attachment of mature sporophylls to mediumsized boulders as explored in our present study has the potential to overcome this problem. (1) Sufficient space is guaranteed for fixation of freshly released spores. (2) The developing recruits have ample chances to acclimate to their habitat. (3) This method could be initiated any time, since
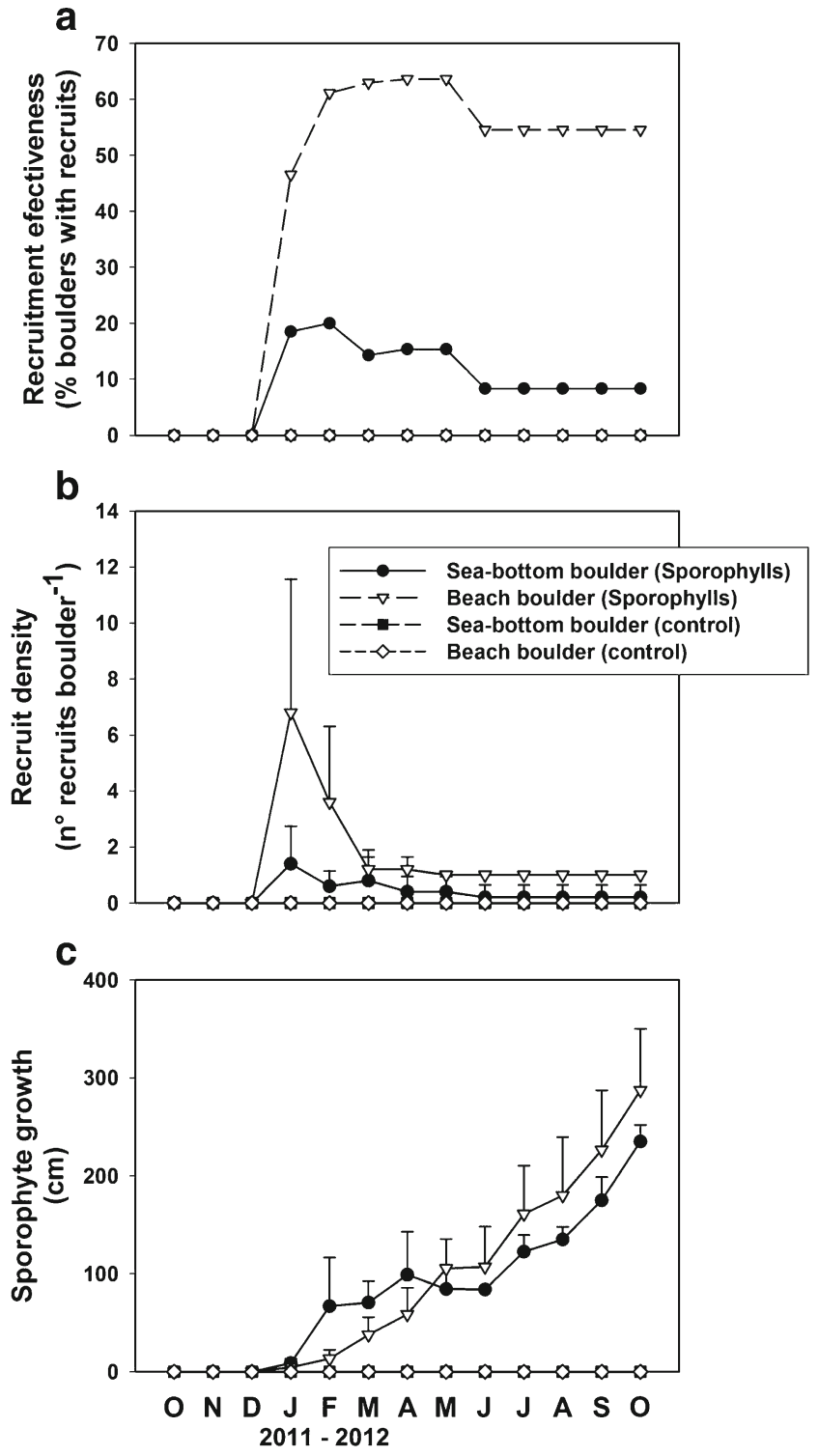

Fig. 7 Recruitment and growth of $M$. integrifolia sporophytes after spore seeding through cotton gauze sleeves: a recruitment effective ness, b recruit density, c sporophyte growth. Error bars indicate stan dard deviation

mature reproductive individuals are found throughout the year in M. integrifolia populations of northern Chile. This last assumption, however, should be verified since several kelps have exhibited seasonal variation on their propagule viability (Westermeier and Möller 1990; Lee and Brinkhuis 1988; Murúa et al. 2013).

Laboratory produced $M$. integrifolia seedlings from Bahia Chasco spores reached $10 \mathrm{~cm}$ size within 30 weeks, while previous experiments documented considerably faster growth of $7 \pm 2 \mathrm{~cm}$ in 18 weeks with stock from nearby Caldera City (Westermeier 2009). It seems that our laboratory-based method of Macrocystis seedling production in free-floating condition performs most efficiently with $M$. 
pyrifera from southern Chile and M. pyrifera $\mathrm{x}$ integrifolia hybrid strains (Westermeier 2009; Westermeier et al. 2010). In M. integrifolia, we obtained good results with an intermediate approach. Various artificial substrates such as PVC or ceramic plates, polypropylene rope fragments, or plastic grids were directly seeded with spores and incubated in the hatchery up to sporophyte sizes of a few mm before explantation to the sea (Westermeier et al. 2012b).

Generally, the success of kelp explants or transplants depends on initial size. Larger individuals exhibit more resilience and better survival than younger stages, which are subject to higher mortality and greater risks of detachment (Hernandez-Carmona et al. 2000; Druehl 1978). Similarly, transplants are better acclimated than explants from hatchery culture and may exhibit superior results for restoration purposes (Correa et al. 2006; Westermeier et al. 2012b, c). In our present study, however, all trials with explantation of $10-\mathrm{cm}$ seedlings produced in the laboratory were successful. Newly formed haptera established good fixation, growth proceeded to reproductive maturity. Released spores colonized adjacent areas in a similar manner as reported by Correa et al. (2006) for L. nigrescens transplants and by Westermeier et al. (2013a, b) for M. integrifolia outplants, transplants, and holdfast fragments. Another feature of M. integrifolia, its elaborate stoloniferous holdfast system, easily regenerates whole thalli from cut-out fragments. Fronds from such regenerates reach reproductive maturity earlier than their parent thallus (Westermeier et al. 2013a, b).

In our explantation experiments with Macrocystis seedlings, use of elastic bands proved to be a very efficient, nondamaging, and low cost way to fix holdfasts to a prospective support. Although it cannot be used on flat surfaces, it is well applicable on medium-sized boulders and artificial reef constructions as recommended by several authors for kelp restoration projects (Terawaki et al. 2000; Deysher et al. 2002). As an alternative to elastic bands, adhesive glues are feasible for flat surfaces or big rocks. Various types of glues have been recommended for kelp transplantation experiments, with controversial results. Vásquez and Tala (1995) have used non-epoxy cement glue to attach L. nigrescens transplants in northern Chile, but mortality was total within 2 weeks. In contrast, Serisawa et al. (2003) transplanted specimens of Ecklonia cava with cyanoacrylate glue and obtained more than $80 \%$ survival within 4 months. In our study, survivals reached $40 \%$ in 9 months, although recent work revealed this percentage can be increased if solid and more stable substrata are used (Westermeier et al., unpublished data). Cyanoacrylate glue showed excellent compatibility with our M. integrifolia seedlings: holdfasts attached to substrata in less than $30 \mathrm{~s}$, the glue hardened quickly in air or seawater contact and sporophytes regenerated new haptera. Critical aspects for use of acrylate glue are that it must be applied with great care, since excess material causes biological damage on the substratum, and that access to this material is difficult for the local fishermen. In addition, the feasibility of both elastic band and acrylate glue in Chilean kelps $L$. nigrescens (Westermeier et al. 2013b) repopulation attempts have been ascertained in Atacama coast as well, with better results of second attachment method. Another innovative and effective system for kelp attachment by the holdfast was developed by Correa et al. (2006) for L. nigrescens, who used Vexar nets screwed to rocky intertidal platforms with stainless steel bolts, previous rocks perforation. Clearly, the exposed environments-where L. nigrescens species exists - demand more stable fixation methods than M. integrifolia subtidal habitats, such as powerful glues or strong nets.

Both lines of our study, repopulation by spore seeding and explantation of hatchery-grown seedlings of $M$. integrifolia were successful under experimental scales. However, the most important and fruitful experiences of repopulation - in terms of productivity, survivorship, and positive impacts on the ecosystem - involve major dimensions of restoration, through kelp beds creation. Artificial reefs or kelp beds allow not only the growth of kelp standing stock, but also the proliferation of habitat of several important marine organisms, with a consequent increase of their abundance (Terawaki and Hasegawa 2001; Terawaki et al. 2003). Restoration is however, a transdisciplinal issue that should be addressed by different approaches in ecological science, in a macroscale. The next step for M. integrifolia repopulation is, therefore, to upscale dimensions and to perform pilot scale experiments in localities where populations of this seaweed are disturbed or completely depleted by anthropogenic or natural impact. By the way, in recent trials the Universidad Austral de Chile have restored with M. integrifolia more than $1,000 \mathrm{~m}^{2}$ of sandy substrata in Bahia Chasco, creating kelp patches with boulders with the three repopulation techniques above described (Westermeier et al., unpublished data).

Acknowledgments Funds for restoration activities were provided by Fondo para la Innovación y la Competividad FIC 20102011 grants funded by Atacama Regional Government to RW. The valuable sug gestions from two anonymous reviewers are really acknowledged. We also thank the substantial field assistance by Claudio Soza and local fishermen from Bahia Chasco.

\section{References}

Carney LT, Waaland JR, Klinger T, Ewing K (2005) Restoration of the bull kelp Nereocystis luetkeana in nearshore rocky habitats. Mar Ecol Prog Ser 302:49 61

Correa JA, Lagos NA, Medina MH, Castilla JC, Cerda M, Ramírez M, Martínez E, Faugeron S, Andrade S, Pinto R, Contreras L (2006) Experimental transplants of the large kelp Lessonia nigrescens (Phaeophyceae) in high energy wave exposed rocky intertidal habitats of northern Chile: experimental, restoration and manage ment applications. J Exp Mar Biol Ecol 335:13 18 
Demes KW, Graham MH, Suskiewicz TS (2009) Phenotypic plasticity reconciles incongruous molecular and morphological taxonomies: the giant kelp, Macrocystis (Laminariales, Phaeophyceae), is a monospecific genus. J Phycol 45:1266 1269

Deysher LE, Dean TA, Grove RS, Jahn A (2002) Design considerations for an artificial reef to grow giant kelp (Macrocystis pyrifera) in Southern California. ICES J Mar Sci 59:S201 S207

Druehl LD (1978) Distribution of Macrocystis integrifolia in British Columbia as related to environmental parameters. Can J Bot $56: 6979$

Evans GC (1992) The quantitative analysis of plant growth. In: Evans GC (ed) Studies in Ecology. Blackwell, Oxford, pp 247254

García AE, Carmona RJ, Lienqueo ME, Salazar O (2011) The current status of liquid biofuels in Chile. Energy 36:2077 2084

Hernandez Carmona G, García O, Robledo D, Foster M (2000) Restoration techniques for Macrocystis pyrifera (Phaeophyceae) populations at the southern limit of their distribution in Mexico. Bot Mar 43:273 284

Lee JA, Brinkhuis BH (1988) Seasonal light and temperature interac tion effects on development of Laminaria saccharina (Phaeophyta) gametophytes and juvenile sporophytes. J Phycol 24:181 91

Macaya EC, Zuccarello GC (2010) DNA barcoding and genetic diver gence in the giant kelp Macrocystis (Laminariales). J Phycol 46:736 742

Macchiavello J, Araya E, Bulboa C (2010) Production of Macrocystis pyrifera (Laminariales; Phaeophyceae) in northern Chile on spore based culture. J Appl Phycol 22:691 697

Murúa P, Westermeier R, Patiño DJ, Müller DG (2013) Culture studies on early development of Lessonia trabeculata (Phaeophyceae, Laminariales): seasonality and acclimation to light and tempera ture. Phycol Res 61:145 153

North WJ (1971) The biology of giant kelp beds (Macrocystis) in California. Nova Hedwigia 32, pp 600

Serisawa Y, Aoki M, Hirata T, Bellgrove A, Kurashima A, Tsuchiya Y, Sato T, Ueda H, Yokohama Y (2003) Growth and survival rates of large type sporophytes of Ecklonia cava transplanted to a growth environment with small type sporophytes. J Appl Phycol 15:311 318

Sernapesca (2011) Anuario Estadístico de Pesca. Ministerio de Economía Fomento y

Starr RC, Zeikus JA (1993) UTEX: the culture collection of algae at the University of Texas at Austin. J Phycol 29/Suppl:1 106

Stekoll MS, Else PV (1996) Cultivation of Macrocystis integrifolia (Phaeophyceae; Laminariales) in southeastern Alaskan waters. Hydrobiologia 204/205:445 451

Terawaki T, Yoshida G, Yoshikawa K, Arai S, Murase N (2000) "Management Free" techniques for the restoration of Sargassum beds using subtidal, concrete structures on sandy substratum along the coast of the western Seto Inland Sea, Japan. Environ Sci 7:165 175
Terawaki T, Hasegawa H, Arai S, Ohno M (2001) Management free techniques for restoration of Eisenia and Ecklonia beds along the central Pacific coast of Japan. J Appl Phycol 13:13 17

Terawaki T, Yoshikawa K, Yoshida G, Uchimura M, Iseki K (2003) Ecology and restoration techniques for Sargassum beds in the Seto Inland Sea, Japan. Mar Pollut Bull 47:198 201

Vásquez J, Tala F (1995) Experimental repopulation of Lessonia nigrescens (Phaeophyta, Laminariales) in intertidal areas of north ern Chile. J Appl Phycol 7:347 349

Westermeier R (2009) Maricultura de Macrocystis en Chile: introducción a técnicas hibridación, caracterización de clones parentales e hibridación recíproca. Informe final proyecto FONDEF D04I1288 (Conicyt), 102 pp

Westermeier R, Möller P (1990) Population dynamics of Macrocystis pyrifera (L.) C. Agardh in the rocky intertidal of southern Chile. Bot Mar 33:363 367

Westermeier R, Patiño DJ, Piel MI, Müller DG (2005) Manual del cultivo de alga parda Macrocystis pyrifera (huiro), Chile. Proyecto FONDEF D00I1144 (Conicyt). Universidad Austral de Chile, 38 pp

Westermeier R, Patiño DJ, Piel MI, Maier I, Müller DG (2006) A new approach to kelp mariculture in Chile: production of free floating sporophyte seedlings from gametophyte cultures of Lessonia trabeculata and Macrocystis pyrifera. Aquac Res 37:164 171

Westermeier R, Patiño DJ, Müller DG (2007) Sexual compatibility and hybrid formation between the giant kelp species Macrocystis pyrifera and $M$. integrifolia (Laminariales, Phaeophyceae) in Chile. J Appl Phycol 19:215 221

Westermeier R, Patiño D, Müller H, Müller DG (2010) Towards do mestication of giant kelp (Macrocystis pyrifera) in Chile: selection of haploid parent genotypes, outbreeding, and heterosis. J Appl Phycol 22:357 361

Westermeier R, Patiño D, Murúa P, Muñoz L, Ruiz A, Müller DG (2012a) Variations of chemical composition and energy content in natural and genetically defined cultivars of Macrocystis from Chile. J Appl Phycol 24:1191 1201

Westermeier R, Patiño D, Murúa P, Muñoz L, Ruiz A, Atero C (2012b) Manual de repoblamiento de Macrocystis integrifolia en la región de Atacama. Proyecto FIC FNDR 2010 Región de Atacama. Universidad Austral de Chile. 47pp

Westermeier R, Murúa P, Patiño D, Muñoz L, Ruiz A, Atero C, Müller DG (2013a) Utilization of holdfast fragments for vegetative prop agation of Macrocystis integrifolia in Atacama, Northern Chile. J Appl Phycol 25:639 642

Westermeier R, Murúa P, Patiño D, Muñoz L, Ruiz A, Müller DG (2013b) Growth patterns of Chilean kelps holdfast after fragmenta tion: a novel repopulation approach. Proceedings of 21 st International Seaweed Symposium 21, 242 243. www.xxiseaweedsymposium.org

Zar JH (1999) Biostatistical analysis, 4th edn. Prentice Hall, Englewood Cliffs, NJ, p 663 p 